\title{
Corrigendum
}

\section{Editorial Foreword-Corrigendum}

https://doi.org/10.1017/S0010417521000220. Published online by Cambridge University Press, 29 June 2021

In the Editorial Foreword of the July 2021 issue of Comparative Studies in Society and History, Charles A. McDonald's name was misspelled as MacDonald.

\section{REFERENCE}

2021. Editorial Foreword. Comparative Studies in Society and History 63, 3: 531-33. https://doi.org/10.1017/S0010417521000220. 